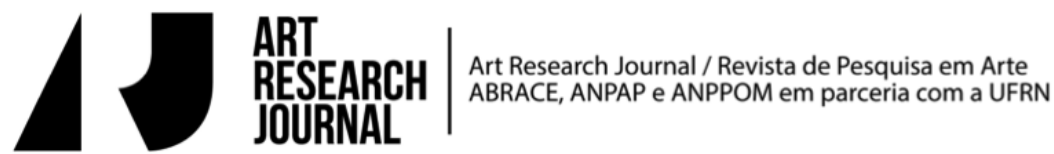

\section{O museu de cada um: montagens e fantasmas}

Sheila Cabo Geraldo Universidade do Estado do Rio de Janeiro, Rio de Janeiro, Brasil sheicg4@gmail.com

\section{Os fantasmas}

Foi a memória que me fez escrever esse artigo. Mais especificamente, foi um exercício de rememoração que me fez voltar a dois artistas que expuseram na $55^{\circ}$ Bienal Veneza, de 2013, e que acionaram a reflexão sobre a história da arte como história das imagens, implicando em uma história de fantasmas e por montagem. Os dois trabalhos dos artistas que ativaram essas reflexões, reproduzidos aqui lado a lado são: Straight, de Ai Weiwei (Foto 1) e Apollos's Ecstasy, de Walter de Maria (Foto 2).

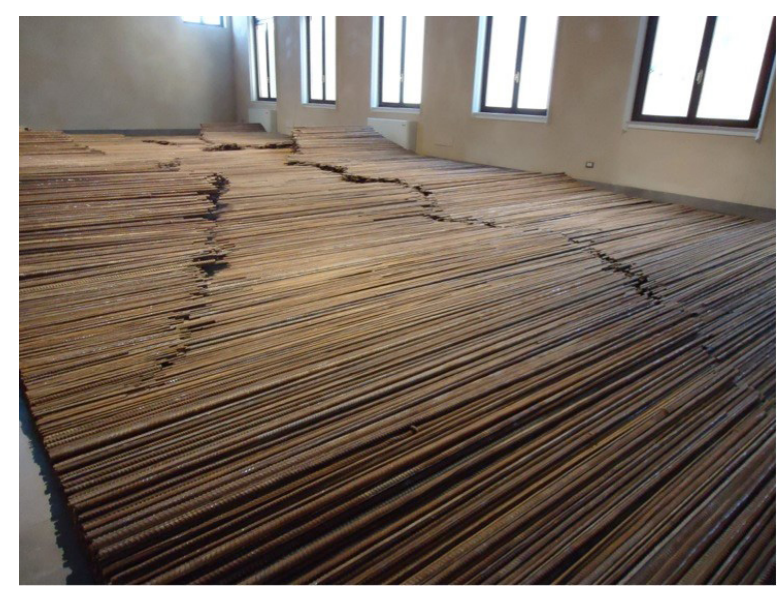

Foto 1: Straight.Ai Weiwei, 2008

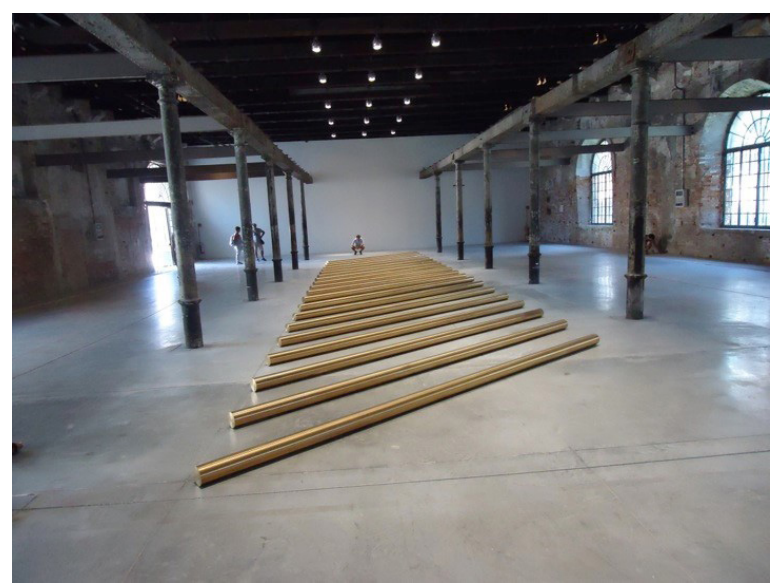

Foto 2: Apollo's Ecstasy, Walter de Maria, 1990 
Straight ${ }^{1}$ foi feito com vergalhões resgatados dos desmoronamentos de escolas no terremoto de 2008, na cidade de Sichuan, na China, onde morreram mais de quinhentas crianças. AiWeiwei, que havia se apropriado dos escombros, malha os vergalhões até ficarem novamente retos e os amontoa em um espaço fechado, aproximando-os, formalmente, do trabalho de Walter de Maria, artista de referência da Minimal e da Land Art dos anos 1970 e que, na mostra de Veneza, encontrava-se no Arsenal, em outro contexto. Massimiliano Gioni, curador daquela Bienal havia escrito no texto de apresentação:

[.... Walter de Maria celebra a muda, gélida pureza da geometria. Como todos os trabalhos desse artista legendário, essa escultura [Apollo's Ecstasy] abstrata é o resultado de um complexo cálculo numerológico - um sistema próprio, no qual as possibilidades infinitas da imaginação são reduzidas a uma extrema síntese. (Gioni, 2013, p. 21).

Embora tenha sido quase sempre associado ao Minimalismo, ao Conceitualismo e à Land Art, o trabalho de Walter de Maria não pode ser pensado apenas a partir dessas definições, que recaem em uma leitura por categorias encadeadas. Assim é que, no texto que acompanha o trabalho do artista, do mesmo catálogo, assinado por Chris Wiley², há uma referência a sua longa trajetória como artista da terra, que se caracterizou pelas experimentações com as grandes escalas, mas, sobretudo refere-se aos trabalhos do final dos anos 1970 e início dos 80, em que, para além dos austeros arranjos geométricos, que caracterizaram as inserções de Land Art, apareciam alusões a sistemas não formais, ou advinhatórios, como $360^{\circ}$ I-Ching/64 Esculturas, de 1981. É nesse contexto que Apollo's Ecstasy foi apresentado, ou seja, correspondendo a presença de uma dicotomia entre razão e êxtase, da mitologia clássica, que aparecem indissociáveis no trabalho.

Apollo's Ecstasy, de 1990, que alinha varas de metal (latão), em sua muda síntese, aponta, como indica o próprio título, para enigmáticas contradições, um certo des-

1 Straight foi apresentado em uma das mostras paralelas da Bienal de Veneza de 2013 e ocupava o Zuecca Project Space, Complexo de Zitelle, na Giudecca. O mesmo trabalho já havia sido mostrado no Hirshhorn Museum, em Washington D.C, em 2008.

2 WILEY, Chris. Walter de Maria. 55th International Art Exhibition. Il Palazzo Enciclopedico. Veneza, p. 74. Catálogo 
vio na ordem apolínea, já que as barras ali deitadas ao chão mostram pequenos desalinhos, diferenças de direção, que lançam o olhar para a presença dos inquietos desarranjos, os quais teimam em aparecer como impurezas nas imagens, para além do ascetismo visual. Como escreveu Didi-Huberman, citando Warburg a propósito da defesa antropológica da imagem em Ghirlandaio, onde coexistiriam a angústia da morte e a fé na ressureição: "O que se retém aqui é a lição nietzschiana fundamental: a arte não é "desinteressada" como acreditava Kant. Ela não cura, não sublima, não acalma absolutamente nada" (Didi-Huberman, 2013 a, p.128).

A defesa antropológica da imagem em Warburg está na base de sua história antropológica/cultural da arte, em que as imagens constituem a história enquanto sintoma e sobrevivência, ou seja, enquanto irrupções temporais - que Benjamin conceituou como próprias do tempo de Agoras - e retornos, que Warburg denominou Nachleben der Antike (sobrevivência do antigo). Isso muda e desloca a história da arte no início do século $\mathrm{XX}^{3}$, abrindo-a para uma opção historiográfica marcada não mais pelos marcos biomórficos, mas por estratos híbridos e complexos, em que o passado e o presente se interpenetram em configurações por vir. Quando Warburg publica Dürer e a Antiguidade italiana (Warburg, 1999, p.553), abre o texto de 1905 com a imagem do desenho Morte de Orfeu ${ }^{4}$, uma representação do momento tenso que antecipa o despedaçamento do corpo clássico do herói pelas Mênades enfurecidas e contorcidas. De acordo com Didi-Huberman, essa atenção ao desenho do pintor e gravador alemão é fundante da contestação dos modelos epistêmicos em uso na história da arte desde Vasari até Winckelmann, forjados no modelo cíclico natural (vida-morte, grandeza-decadência). O que Warburg indagaria diante dessa imagem descontrolada das Mênades - assim como arriscamos perguntar diante do desvio do proclamado ascetismo inefável de Walter de Maria -, é se não haveria uma outra temporalidade na história das imagens que não fosse a da transmissão por imitação sucessiva, empregada pelos historiadores desde o Renascimento e que se reafirmara em Winckelmann.

3 Warburg inicia a reflexão sobre a história da arte já em sua tese de doutorado, avançando com o texto sobre os índios Pueblo e concretizando suas experimentações no Atlas Mnemosyne. Cf. Aby Warburg, The Renewal of Pagan Antiquity. Contributions to the Cultural History of The European Renaissance.

4 Albert Dürer, A Morte de Orfeu, 1494, Tinta sobre papel. Hamburg Kunsthalle. 
Quando explicitou o conceito de Dynamogramm - que entendia como uma espécie de grafia da imagem-sintoma - (Didi-Huberman, 2013a, p. 154), Warburg estaria tratando especialmente dessa outra temporalidade, que se apresenta como uma sobrevivência do pathos (Pathosformel) e que apareceria nos passionais drapeados helenísticos, exemplarmente reapresentados não só nas Mênades que atacam Orfeu, mas também nas argilas da Lamentação sobre Cristo morto, que Niccolò dell'Arca fez em 1480. No grupo escultórico, o drapeado, mas também o gestual retesado de Madalena corresponderia ao retorno do desejo desenfreado das antigas bacantes, que teriam passado despercebidos aos renascentistas cristãos italianos avaliados por Vasari, mas que fantasmaticamente reaparecem no desenho de Dürer e na escultura de dell'Arca.

Warburg introduz, assim, na história da arte o que ficou conhecido como "modelo fantasmático", que abre a história para pensamentos incertos e conflitantes, próximos do que Freud (Didi-Huberman, 2013a, p. 243) teorizou como sintomas. O fantasmático na história seria coincidente com uma espécie de exumação dos documentos de arquivo, quando afloram os "timbres de voz inaudíveis, vozes desaparecidas, vozes ocultas em uma grafia ou em movimentos particulares de um diário íntimo..." (Didi-Huberman, 2013a, p. 36). Nessa perspectiva, as imagens levam o historiador para a emergência de um conjunto de processos tensos, para uma história temporalmente repleta de desorganizados "agoras", como escreveu Walter Benjamin. (Benjamin, 2006, p. 503).

Retomando as duas obras que desencadearam essas reflexões, observamos que de maneira semelhante a Apolos's Ecstasy, Straight, de Ai Weiwei, estaria também entre a visualidade composta pela instalação fria e muda dos vergalhões alinhados e a expansão fantasmática da imagem que, nesse caso, corresponde aos emaranhados de vergalhões, que se tem acesso pelo vídeo mostrado em sala contígua. É pelas imagens videográficas do que restou do terremoto, ou seja, dos escombros, com ferros retorcidos, que se percebe a densidade histórica de Straight. Só ali, na sala de fora, quando são apresentadas as filmagens do desabamento, a imagem se revela em seu alargamento e sobreposição. Straight é, como Apollo's Ecstasy mais que geometria e mudez. 


\section{A bienal-montagem}

Palácio Enciclopédico foi o tema geral da $55^{\circ}$ Bienal de Veneza e se referia ao projeto utópico de Maurino Auriti, de 1955, que é quase um projeto de museu imaginário, ou de uma extensa biblioteca (Flaubert), na qual se poderia concentrar todo o conhecimento do mundo, ou seja, uma cosmologia que conciliaria o pessoal e o universal, o subjetivo e o coletivo, o específico e o geral, onde foram incluídas as contradições, inconstâncias, incoerências e sobreposições das instalações de Ai Weiwei e Walter de Maria.

Como no trabalho de Auriti, a Bienal combinou trabalhos de arte contemporânea com artefatos históricos e objetos encontrados. Tanto a Bienal quanto o Palácio seriam, assim, uma grande montagem de pensamentos e ações artísticas e não artísticas. Posto dessa maneira, a presença de ambos os trabalhos na Bienal (AiWeiwei e Walter de Maria) nos faz tanto questionar uma aproximação histórica da arte no registro que remonta ao moderno processo de história da arte, em que a semelhança formal se impõe como uma salvação unificadora (a história por estilos), como também nos exige uma elaboração de procedimentos capazes de dar conta de formulações em outra sintonia, que não anule, pelo discurso da forma, as possibilidades de desfolhar camadas de sentido, onde se encontram não só as semelhanças submersas, mas também as contradições e as ressonâncias.

De uma maneira muito apropriada para a discussão da história das imagens que proponho aqui observar, destaco, ainda, a exposição paralela à Bienal (Manet, Ritorno a Venezia), que se pôde visitar na mesma época no Palácio Ducal, onde estavam expostas as pinturas Olympia, de Manet e a Vênus de Urbino, de Ticiano. A curadoria, através da disposição das obras, ressaltava a semelhança formal entre elas, assim como o peso da influência dos pintores venezianos na formação de Manet.

Não resta dúvida de que Manet manteve da Vênus de Ticiano não só a pose da modelo, mas também a composição do quadro. Entretanto, escreveu T. J. Clark (Clark, 2004, p. 154), contrariamente a de Ticiano, a pintura de Manet é marcada pelos signos movediços e inconsequentes de sua época, revelando um forte ceticismo em relação aos modos como a similitude era assegurada até então. Douglas Crimp, citando Michael Fried (Crimp, 2005, p.45), também defende que Manet teria se distanciado dos artistas que há muito vinham fazendo em pintura referências 
aos mestres do passado, pois exercia na cópia uma literalidade tão desconcertante, que abriria, assim, um outro debate, dessa vez epistemológico, que referia-se à impossibilidade de, a partir da década de 1860, se continuar a fazer a história que procura as origens de cada imagem e as insere em uma linha de influências e analogias, já que a obviedade das cópias de Manet revelava uma aguda consciência histórica. Desconsiderando-se o acanhamento teórico do discurso curatorial, que revelava um certo deslumbramento pela semelhança formal, assim como justificava biograficamente a influência dos venezianos sobre Manet - que havia passado três temporadas em Veneza -, é que se chega a concluir, com Crimp, que é a consciência histórica que nos faz entender o quanto passa a ser inevitável que a partir de Manet... "toda pintura [...] passa a fazer parte da imensa superfície da pintura"5. É nessa superfície, mas especialmente de suas fissuras, que emergem os fantasmas, uma propriedade das aproximações, que fazem ressoar as mais intensivas formas de arte e de cultura.

Entender a arte como uma imensa superfície foi o que levou André Malraux a elaborar o projeto de um Museu Imaginário de reproduções fotográficas, desenvolvido logo depois da Segunda Grande Guerra, onde a moderna pintura de Manet ganha especial destaque não só pelas semelhanças formais entre a Olympia e a Vênus de Urbino, como também pela proximidade da retórica do fuzilamento, que coloca lado a lado Os fuzilamentos de 3 de maio de 1808, de Goya e A execução do Imperador Maximiliano, de Manet.

O Museu imaginário desenvolve, assim, uma história de similitudes (formais e retóricas), não de influências. A fotografia teria a capacidade de reduzir, como paródia, a heterogeneidade, como escreve Douglas Crimp, permitindo que a diversidade de objetos, fragmentos de objetos e detalhes façam parte do sistema do museu sem paredes. É com base na homogeneidade fotográfica que Malraux passa a fazer a história da arte por aproximação, seja de objetos materialmente diversos, seja de imagens temporalmente dissemelhantes. Mas, talvez, sua principal relevância seja uma espécie de montagem visual experimental, que o historiador pensa dar conta, em arte, de uma herança cultural maior e mais expandida que a produção ocidental de matriz greco-latina. O Museu, formado por fotografias de obras de

5 Foucault, M. Apud Crimp, p. 46 
várias civilizações e culturas, cria, como escreveu Malraux, "um estilo babilônico" (Malraux, 1953, p.44), lançando uma forma de pensar a arte por imagens, que abre a história da arte para novos objetos, novos territórios, objetos nem sempre visíveis em museus de arte, como as moedas, mas, sobretudo, para objetos desconhecidos dos especialistas ocidentais.

Desde os anos 1930 Malraux vinha pensando sobre o papel central da reprodução das imagens na construção da nossa herança cultural. É com base na reprodução fotográfica e no cinema que a sua obra ensaística passa a apontar para uma abertura no domínio artístico (além da mudança no estatuto da arte), o que também se estende para a história da arte, uma vez que ao aproximar imagens de objetos materialmente diversos e temporalmente dissemelhantes, aciona o que Walter Benjamin teorizou como uma história por montagem (Benjamin, 2006, p. 499). A estratégia de montagem de Malraux partiu da ideia de que essas imagens seriam publicadas lado a lado em um livro, uma forma de fazer as obras dialogarem diretamente. Dessa maneira, usa não só a sucessão de imagens de uma mesma escultura - com fotos que mostram a frente e a parte de trás e fotos que mostram a escultura em dois pontos de vista -, produzindo uma história de avaliação da unidade, como também a montagem de imagens de duas obras diferentes.

Didi-Huberman (Didi-Huberman, 2013b, p. 20) afirma que Malraux conheceu a obra de Walter Benjamin, sobretudo o texto $A$ obra de arte na época da reprodutibilidade técnica, a partir do qual desenvolveu seu Museu Imagináro de fotografias. Havia mesmo recebido de Benjamin uma cópia do texto a ele dedicada. Embora se reconheça a importância da obra de Einsenstein sobre Malraux, certamente o historiador e ensaísta percebera o quanto as teorias estético-filosóficas de Benjamin realizavam o que as vanguardas históricas produziam em seus programas como montagem, quando as experiências artísticas e poéticas reconstroem um universo incerto a partir de uma tradição esfacelada. Ernest Bloch ${ }^{6}$ identificara na própria escrita histórica de Benjamin a concepção de montagem. Bloch estabeleceu uma ligação direta entre Rua de Mão Única, que Benjamin escreveu como parte do projeto das Passagen-Werk (Passagens) e o que chamou de Surrealismo pensante. Tanto Breton quanto Aragon, como escreve Benjamin (Benjamin, 1985,

6 Apud MUNSTER, Arno. Ernst Bloch: filosofia da praxis e utopia concreta, p. 68. 
p.91) haviam visto na imagem não-contemplativa da fotografia” uma potente força revolucionária e política naquele momento em que a modernidade avançava como a tempestade sobre as asas do anjo da história, deixando abaixo de si um amontoado de escombros.

O Museu Imaginário de fotografias, que Malraux começa a desenvolver no final dos anos 1940, ainda que influenciado pelas teorias de Benjamin sobre a reprodutibilidade técnica da arte na fotografia (que impulsiona a mudança no estatuto da arte), tem, entretanto, para Malraux, dois sentidos diversos e complementares: é um museu de imagens, mas é também um museu do imaginário. 0 museu de imagens remete diretamente às técnicas de reprodução, que, como vimos, segue o pensamento de Walter Benjamin. Permite que as pessoas possam ver tudo aquilo que, além de distante no espaço e no tempo, é intransportável, tudo aquilo que nem mesmo os grandes museus podem adquirir. Como escreveu, ainda, Didi-Huberman, o Museu abre um álbum fotográfico da cultura universal, que se pode comparar com uma antropologia das imagens instaurada quase meio século antes por Aby Warburg (Didi-Huberman, 2013b, p. 23).

Entretanto, para Malraux o sentido do Museu vai além da difusão de conhecimento pelas imagens de arte. Para o escritor e ensaísta, o museu também é um lugar mental, um espaço imaginário, sem fronteiras, que nos habita. Se o espírito humano é capaz de reter as formas que admira, o museu se alarga. Deixa de ser apenas um museu formado de reproduções para ser aquele que se pode conceber mentalmente ou rememorar. É como se as formas, enquanto magia, se apoderassem de nós e assim sobrevivessem em nós (Silva, 2002, p. 187) ${ }^{8}$. Dessa maneira, cada um teria

7 A presença da fotografia no movimento surrealista inclui as fotos banais de Boiffard, para Nadja, as de Man Ray e Brassaï para L'amour fou, ambos de Breton e as fotografias de Man Ray para D'un certain automatisme du gout, de Tzara, publicado na revista Minotauro. Caberia citar, ainda, as tiragens de negativos e o recurso de exposições múltiplas, ou superposições, assim como as manipulações com espelhos, que remeteriam às repetições sem principal do mundo mecânico. Estariam também nesse leque surrealista as fotografias solarizadas de Man Ray, que por seu efeito fantasmático, seduziram especialmente os poetas, que as identificavam com "objetos-sonhos", mas também as de Raul Ubac, que derretia a emulsão e fazia com que suas imagens tivessem o efeito de evocação onírica. Cf. Krauss, R. O Fotográfico.

8 SILVA, Edson Rosa da. O Museu imaginário e a difusão da cultura. Semear. Disponível em <http:// www.letras.puc-rio.br/unidades\&nucleos/catedra/revista/6Sem_14.html>. Acesso em abr. 2015. 
um Museu Imaginário, pois cada um escolhe e deixa que o habite um acervo de obras que retém como rememoração. É assim que se poderia ampliar o escopo das imagens da Vênus de Ticiano, indo além de Manet, até Goya e Hannah Hoch.

Fica claro, portanto, que o Museu Imaginário não se reduz ao parentesco de formas e retóricas. É no diálogo constante entre as mais distantes regiões e entre os mais diversos estilos que se estabelece o Museu coerente com o que Malraux chamou de uma "civilização planetária", onde haveria uma infinitude de relações possíveis e onde não cabe um saber único, como se pode ver também no Palácio Enciclopédico de Auriti.

A confrontação de obras na escrita da história e o exercício da montagem como uma "inassimilável pulsação de diferenças" (Didi-Huberman, 2013b, p. 25) parece, mais do que nunca, requerida na abordagem da arte no mundo contemporâneo. Dessa maneira é que me parece que a montagem que Jean Luc Godard realiza em História(s) do cinema - que faz parte do meu Museu Imaginário -, carrega, como fez Malraux, a potência contemporânea de fazer história. Godard trata de pôr em cena uma estranheza do familiar para fazer aparecer outra ordem que só se descobre nos intervalos, no espaço entre, enquanto um mistério, como disse o próprio cineasta9. Godard produz o que Agamben (Agamben, 2009, p.72) chamou de uma arqueologia do presente, que se torna um lugar de encontro de tempos interpolados ${ }^{10}$. Nesse processo, segundo Jacques Rancière, Godard faz coincidir dois princípios: a vida autônoma da imagem, como potência singular da forma muda, que se oporia ao que chama de "a letra morta do texto" (Rancière, 2012, p. 43), e as combinações de signos linguísticos com elementos visuais e sonoros, "que fazem dos conjuntos de fragmentos visuais "imagens", isto é, relações entre uma visibilidade e uma significação (Idem, 2012, p. 43).

Nas palavras de Jacques Rancière:

O cinema que nos conta aparece como uma série de apropriações das outras artes. E ele o apresenta num entrelace de palavras, frases e textos, pinturas metamorfoseadas, planos cinematográficos misturados com fotografias ou fitas de cinejornal, eventualmente ligadas por citações musicais. [...] E nesse emaranhado, a própria

9 GODARD, apud RANCIÈRE, J. O destino das imagens. p. 70.

10 AGAMBEN, G. O que é o contemporâneo? E outros ensaios, p. 72. 
noção de imagem, [...] aparece como aquela que tem uma operatividade metamórfica, que atravessa as fronteiras das artes e denega a especificidades dos materiais (Rancière, 2012, p 51).

Interessa-nos, na série de vídeos, sobretudo a montagem da parte 3A, La Monnaie de l'Absolu, cujas primeiras imagens já são aproximações entre a pintura negra Saturno devorando um filho, de Goya, de 1819, e os sussurros do texto de Victor Hugo em que o escritor declara que se a civilização está nos povos, a barbárie está nos governantes. Godard monta ali, em uma frase-imagem, como diz Rancière, a história do cinema como história dos encontros inesperados e das metamorfoses, fazendo emergir, como fantasmas, a violência das guerras de uma maneira em que o tempo passado e o tempo presente ficam emaranhados como fatalidade. A frase-imagem com a pintura de Goya e com o texto de Victor Hugo torna-se, assim, uma potência ativa e disruptiva. Assim é que concluímos que História(s) do cinema é verdadeiramente a história da potência contemporânea de fazer história, mas para compreender essa potência há que se deter, como fez Malraux, no conceito de montagem. ${ }^{11}$ Como escreve Rancière, "a potência da frase-imagem que junta heterogêneos, então, é aquela da distância e do choque que revelam o segredo de um mundo, isto é, o outro mundo [...] por trás das aparências anódinas ou gloriosas." (Rancière, 2012, p. 67). Isso aparece também no título escolhido para a parte 3A, que, ao referir-se ao La Monnaie de I'Absolu - que é o terceiro livro da série Psicologia da Arte, de André Malraux ${ }^{12}$, de que faz parte O Museu imagi-

11 Godard, Jean-Luc e Daney, Serge: Diálogo. In. Histoire(s) du Cinéma, 1988-1998. Barcelona. Intermedio/Cahiers du Cinéma

12 A produção bibliográfica de André Malraux inclui inúmeros ensaios e livros. Destacam-se: Dessins de Goya au Musée du Prado. Genebra: Skira, 1947; Saturne, Essai sur Goya. Paris: Gallimard, 1950); La Psychologie de I'Art, publicada em Genebra pela Skira (composta de: Le Musée Imaginaire [1947], La Création Artistique [1948], La Monnaie de I'Absolu [1950]) e reeditada em 1951 pela Gallimard sob o título Les Voix du Silence; uma outra trilogia chamada Le Musée Imaginaire de la Sculpture Mondiale, publicada pela Gallimard, formada pelos seguintes volumes: Le Musée Imaginaire de la Sculpture Mondiale (1952), Des Bas-reliefs aux Grottes Sacrées (1954) e Le Monde Chrétien (1954). Há ainda os textos da trilogia La Métamorphose des Dieux, publicada pela Gallimard, contendo Le Surnaturel (1957/77), L'Irréel (1974) e L'Intemporel (1976). Importante é, ainda, o texto sobre Picasso, intitulado La Tête d'Obsidienne (Paris: Gallimard, 1974) e o volume intitulado L'Homme Précaire et la Littérature (Paris: Gallimard, 1977). Cf. Silva, E. R. O Museu Imaginário e a difusão da cultura. 
nário. Se na mitologia romana, Saturno - Cronos entre os gregos - é aquele que governa o curso do tempo e garante a inevitabilidade de sua passagem, a história montada por Godard abre a complexidade da história não só para a fatalidade da violência no mundo, mas também para o que Saturno carrega, ou seja, o pathos das contradições entre desejo de controle do tempo e o reconhecimento de sua efemeridade: uma condição de instabilidade que aponta para transformações.

\section{Referências}

AGAMBEN, Giorgio. O que é o contemporâneo? E outros ensaios. Chapecó: Argos, 2009.

BELTING, Hans. Antropologia da Imagem. Lisboa: KKYM, 2014.

BENJAMIN, Walter. Walter Benjamin: magia e técnica, arte e política. Ensaios sobre literatura e história da cultura. São Paulo: Brasiliense, 1985.

BENJAMIN, Walter. Passagens. Belo Horizonte; São Paulo. Editora UFMG; Imprensa Oficial do Estado de São Paulo, 2006.

CLARK, T.J. A Pintura da Vida Moderna: Paris na arte de Manet e de seus seguidores. São Paulo: Companhia das Letras, 2004.

CRIMP, Douglas. Sobre as Ruínas do Museu. São Paulo: Martins Fontes, 2005.

DIDI-HUBERMAN, Georges. A imagem sobrevivente. História da Arte e tempo dos fantasmas segundo Aby Warburg. Rio de Janeiro: Contraponto, 2013(a).

DIDI-HUBERMAN, Georges. L'Album de l'art à l'époque du Musée imaginaire. Paris: Édition Hazan ;Musée du Louvre, 2013 (b).

DIDI-HUBERMAN, Georges. Atlas: Como llevar el mundo a cuestas? Madri: MNCARS, 2010; 2011.

GODARD, Jean-Luc; DANEY, Serge. Diálogo. In: Histoire(s) du Cinéma, 1988-1998. Barcelona: Intermedio;Cahiers du Cinéma, 1988.

GIONI, Massimiliano. Il Palazzo Enciclopedico. Venezia: Fondazione La Bienale di Venezia, 2013. Catálogo.

KRAUSS, Rosalind. O Fotográfico. Barcelona, Editorial Gustave Gili, 2002. 
MALRAUX, André. Le Musée Imaginaire. Paris: Gallimard, 1965.

MALRAUX, André. Les Voix du Silence. Paris: NRF ; La Galerie de la Pléiade, 1953.

MALRAUX, André. O Museu Imaginário. Lisboa: Arte \& Comunicação 70, 2013.

MÜNSTER, Arno. Ernst Bloch: filosofia da praxis e utopia concreta. São Paulo: Editora da Universidade Estadual Paulista, 1993.

RANCIÈRE, Jacques. O destino das imagens. Rio de Janeiro, Contraponto, 2012.

SELIGMAN-SILVA, Márcio. O local da diferença. São Paulo: ed. 34. 2005.

SILVA, Edson Rosa da. O Museu imaginário e a difusão da cultura. Rio de Janeiro: Semear, v. 6, 2002.

WARBURG, Aby. The Renewal of Pagan Antiquity. Contributions to the Cultural History of The European Renaissance. Los Angeles: Getty Research Institute for the History of Art and Humanities, 1999.

WILEY, Chris. Walter de Maria. 55th International Art Exhibition. Il Palazzo Enciclopedico. Veneza, p. 74. Catálogo. 